\title{
Scholarly Success Among Internal Medicine Residents in Canada
}

Katarzyna Jerzak MD, Donald M. Arnold MD MSc, and Shariq Haider MD

\begin{abstract}
About the Author
Katarzyna Jerzak is a medical oncology fellow at the Sunnybrook Odette Cancer Centre in

Toronto, Ontario. Donald Arnold is an assistant professor and Shariq Haider is an associate professor in the Department of Medicine at McMaster University, in Hamilton, Ontario. Correspondence may be directed to haider@mcmaster.ca.
\end{abstract}

\begin{abstract}
Scholar activity is an integral component of postgraduate medical education in Canada. We describe the opportunities in research training among Canadian internal medicine (IM) programs, including program requirements and supportive infrastructure, as well as barriers and enablers of research success.

Methods: An email survey was sent to all program directors (PDs) $(n=14)$ and core IM residents ( $n=1119)$ from English-speaking IM Residency Training Programs in Canada to describe research support and productivity. We evaluated factors associated with achieving an abstract presentation at a scientific meeting or publication of a manuscript in a peer-reviewed journal.

Results: A total of 10 of 14 PDs (71\%) and 308 of 1119 residents (28\%) responded to the survey. Of 10 evaluable programs, 6 had a formal research curriculum and 8 had a mechanism of pairing residents with research mentors. A total of $236(76 \%)$ residents completed a research project during core IM training; of those, $171(55 \%)$ published $(n=84)$ or presented $(n=150)$ their research. A mechanism for linking residents with suitable research mentors, instruction on medical writing, and instruction on data analysis were associated with residents' achieving publication in a peer-reviewed journal.

Conclusion: Requirements for resident research are variable across Canadian IM programs. Instruction on medical writing and statistics, as well as a mechanism to pair residents with suitable research mentors, contribute to resident research success.
\end{abstract}

\section{Résumé}

Les activités de recherche font partie intégrante des études de doctorat en médecine au Canada. Nous décrivons ici les différentes possibilités de formation en recherche offertes par les programmes de médecine interne (MI) au Canada, notamment les exigences et l'infrastructure de soutien des programmes, ainsi que les obstacles et les outils inhérents à la réussite en matière de recherche.

Méthode: Un sondage a été envoyé par courriel à tous les directeurs de programmes (DP) $(n=14)$ et aux résidents inscrits dans les programmes de formation de base en résidence en MI $(n=1119)$ offerts en anglais au Canada pour mieux cerner les mesures de soutien aux activités de recherche et leur efficacité. Nous avons évalué les facteurs qui mènent à la présentation d'un résumé de recherche dans un congrès scientifique ou à la publication d'un article dans une revue à comité de lecture.

Résultats: Un total de 10 DP sur 14 (71\%) et de 308 résidents sur 1119 (28\%) ont répondu au sondage. Sur les 10 programmes pouvant être évalués, 6 ont un curriculum officiel en matière de recherche et 8 ont un mécanisme de jumelage entre résidents et mentors de recherche. Un total de 236 résidents (76\%) ont complété un projet de recherche durant leur formation de base en MI; de ceux-ci, 171 (55\%) ont publié 
( $n=84)$ ou présenté $(n=150)$ leurs travaux de recherche. La présence d'un mécanisme de jumelage entre résidents et mentors de recherche appropriés, de même que l'apport de directives portant sur la rédaction médicale et sur l'analyse des données ont été associés à ce qui permet à un résident de publier dans une revue à comité de lecture.

Conclusion : Les exigences relatives aux activités de recherche poursuivies par les résidents varient selon les programmes canadiens de MI. L'apport de directives portant sur la rédaction médicale et les statistiques, de même que la présence d'un mécanisme de jumelage entre résidents et mentors de recherche appropriés contribuent à la réussite des activités de recherche des résidents.

\section{Summary}

Scholar activity is an integral component of postgraduate medical education in Canada, but with variable expectations across training programs. In light of a growing interest in competencybased curricula, we describe Canadian Internal Medicine (IM) program requirements and supportive infrastructure, as well as barriers and enablers of resident research success.

We surveyed program directors $(n=10 / 14)$ and residents ( $n=308 / 1119)$ from all English-speaking IM training programs across Canada. Descriptive statistics were compiled from both resident and program director responses. Logistic regression was used to determine the association between resident characteristics and i) publication in a peer-reviewed journal, or ii) presentation at a regional, national, or international scientific meeting. Using categorical responses obtained from program directors, we used the chi-square test to evaluate programmatic factors that contribute to the achievement of abstract presentation or manuscript publication by residents.

Based on our findings, we recommend that IM programs include a scholar curriculum with instruction on medical writing and statistics and establish a mechanism for linking residents with suitable research mentors.

\section{Introduction}

Scholar activity is defined as one of seven core competencies in Canadian postgraduate medical education programs, as outlined in the CanMEDS framework, ${ }^{1}$ but there are variable expectations for achieving competency in this area. With a growing concern that fewer physician-scientists are being trained, ${ }^{2}$ it is important that residents receive exposure to research training and opportunities for research experience, as this may guide their future decisions regarding a research career. Furthermore, with reduced resident duty hours and increasing implementation of competency-based curricula, it is critical that requirements for scholar activity are defined and that the importance of research training is not diminished.

This study describes current program requirements and research activities among trainees in Canadian Internal Medicine (IM) residency training programs. Enablers of research output, infrastructure to support resident research, and barriers to research success are described. The ultimate aim of this study is to provide practical suggestions for postgraduate programs for the development of focused research curricula and methods to maximize resident research success.

\section{Methods}

We designed an electronic email survey for program directors and residents to assess the resources available for research in IM training programs and individual experiences among residents in research. We surveyed program directors $(n=14)$ and residents $(n=1119)$ from all 14 English-speaking IM training programs across Canada. A reminder email was sent to program directors and residents, 4 weeks and 8 weeks after the initial invitation. A reasonable gift incentive was offered to encourage participation. Chief medical residents and program assistants were contacted to help disseminate the surveys and ensure compliance locally among IM residents.

The survey for program directors was adapted from an existing tool. ${ }^{3}$ Program directors were asked to indicate the requirements for scholar activity in their program, the type of research projects actually completed by residents, and the proportion that are published or presented at a conference. Presence of infrastructure to support resident research activity (research committee, research director, statistician, funding, etc.) and barriers to resident research were also probed. In addition, if a structured scholar curriculum existed, details regarding its composition were obtained. Categorical (yes/no) and nominal responses (Likert scale) were collected.

Demographic data of residents, including undergraduate medical school, current institution, and year of residency training, are illustrated in Table 1. Information regarding career aspirations (community versus academic career), sub-specialty training, and motivation to complete a research project were also captured. The surveys were piloted by residents $(n=5)$ at McMaster and edited, based on their feedback.

\section{Statistical Analysis}

Descriptive statistics were compiled from resident and program director responses. Logistic regression was used to determine the association between resident characteristics and i) publication in a peer- reviewed journal, or ii) presentation at a regional, national, or international scientific meeting. Using categorical 
Table 1. Demographics of Participating Canadian Internal Medicine Residents and Training Programs

\begin{tabular}{|l|c|}
\hline $\begin{array}{l}\text { Internal Medicine } \\
\text { Program Factor }\end{array}$ & $\begin{array}{l}\text { Percentage of } \\
\text { Participating IM } \\
\text { Programs }\end{array}$ \\
\hline Presence of funding & 50 \\
\hline Mandatory research project & 40 \\
\hline \multicolumn{1}{|c|}{ Mandatory CQI } & 20 \\
\hline Hypothesis driven project & 20 \\
\hline Training in faculty research mentorship & 60 \\
\hline Mechanism to help residents identify mentors & 80 \\
\hline Resident research committee & 50 \\
\hline Resident research director & 80 \\
\hline Forum (on-site) for resident presentation & 100 \\
\hline Research rotation available & 100 \\
\hline Additional research elective time & 100 \\
\hline Research curriculum & 40 \\
\hline \multicolumn{1}{|c|}{ Future career goal } & 28 \\
\hline Resident Characteristic & Percentage of \\
& Participating IM \\
\hline Pesidents
\end{tabular}

$\mathrm{IM}=$ internal medicine. responses obtained from program directors, we used the chisquare test to evaluate programmatic factors that contribute to the achievement of abstract presentation or manuscript publication by residents.

Research ethics approval for this study was obtained from the Hamilton Integrated Research Ethics Board.

\section{Results}

Ten of 14 program directors (71\%) and 308 of 1119 residents (28\%) participated in the study. Fifty one percent of residents were interested in an academic career, and all training levels (years 1-3) were represented. Demographic information regarding IM training programs and participating residents is indicated in Table 1.

\section{Resident Research Output and Program Requirements}

There was significant variability in the type of scholar activity required by Canadian IM training programs for graduation. For example, a topic review with an oral presentation fulfilled graduation requirements for half of the training programs, but did not fulfill requirements for the remaining programs. Discussion of an article at journal club, a case presentation at morning report, and a written case report fulfilled requirements in 30,10 , and 90 percent of surveyed programs, respectively.

The majority of programs did not require a research project for graduation. Two programs mandated a quality improvement project and two different programs required a hypothesisgenerating study. The scholar activities performed by residents are illustrated in Figure 1.

\section{Program Infrastructure and Curriculum}

A dedicated research rotation, additional research elective time, and a forum for presentation were available in all surveyed

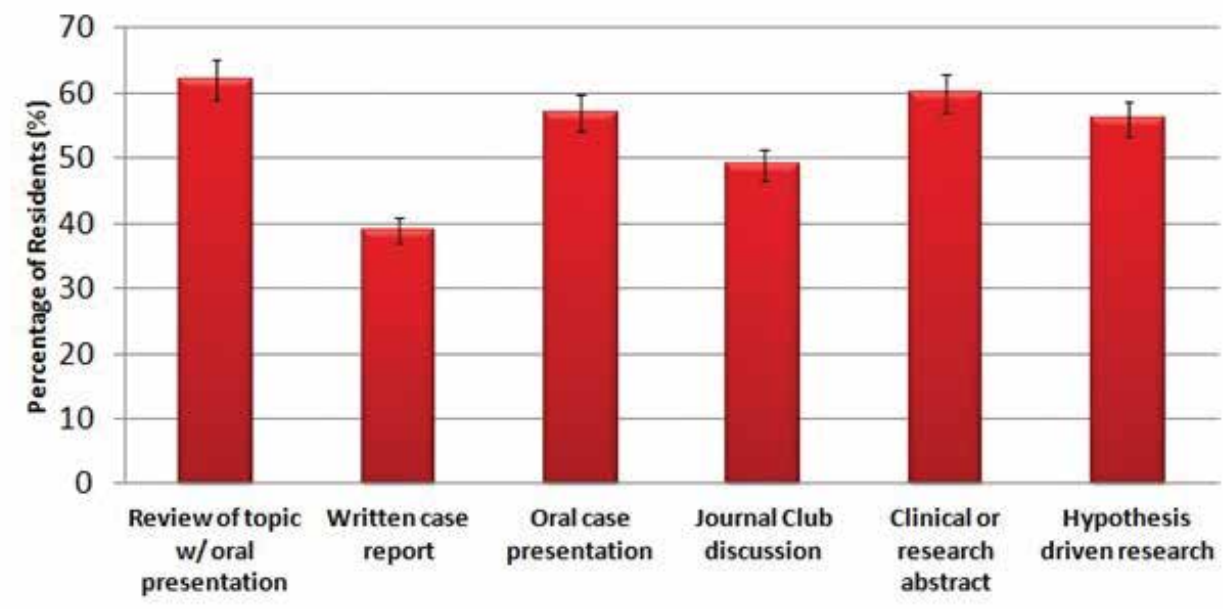

Type of Scholarly Activity

Figure 1. Scholar activity completed by Canadian Internal Medicine residents, as self-reported by residents 
programs. Sixty percent of programs did not have a formal research curriculum.

Regardless of the presence of a structured curriculum, residents reported the thoroughness of teaching of key concepts (thoroughly taught, somewhat taught, or not taught). Critical appraisal and literature searching were felt to be thoroughly taught by 80 percent and 40 percent of residents, respectively. Twenty percent or fewer residents reported thorough teaching of other curricular components, including medical writing and biostatistics/data analysis.

\section{Barriers to Research}

Residents and program directors most commonly cited lack of resident and faculty time as the biggest barriers to resident research. Lack of support with statistical analysis was the third most common barrier identified by residents (44\%), while lack of administrative support was third ranked among program directors (50\%). Lack of a structured research curriculum was the fourth most common barrier, indicated by $43 \%$ of residents and $40 \%$ of program directors. Lack of funding was identified by $30 \%$ of program directors and $46 \%$ of residents.

\section{Factors Influencing Resident Research Success}

Residents' self-motivation, natural interest in research, motivation for fellowship acceptance, and pursuit of a competitive specialty were associated with their success in publishing their research in a peer- reviewed journal (Table 2). Age, undergraduate medical school, and current institution were not associated with research success.

Programs that had a formal mechanism to link residents with research mentors were more likely to have their residents publish their work. Residents who reported thorough teaching of statistics and medical writing as part of their IM training were more likely to publish their work. Thorough teaching of research design, research ethics, and presentation skills were also associated with resident research success (Table 2). The number of residents in the program and presence of a mandatory research project were not significant in predicting publication or presentation.

Table 2. Factors Associated With Resident Research Success in Publication and Presentation

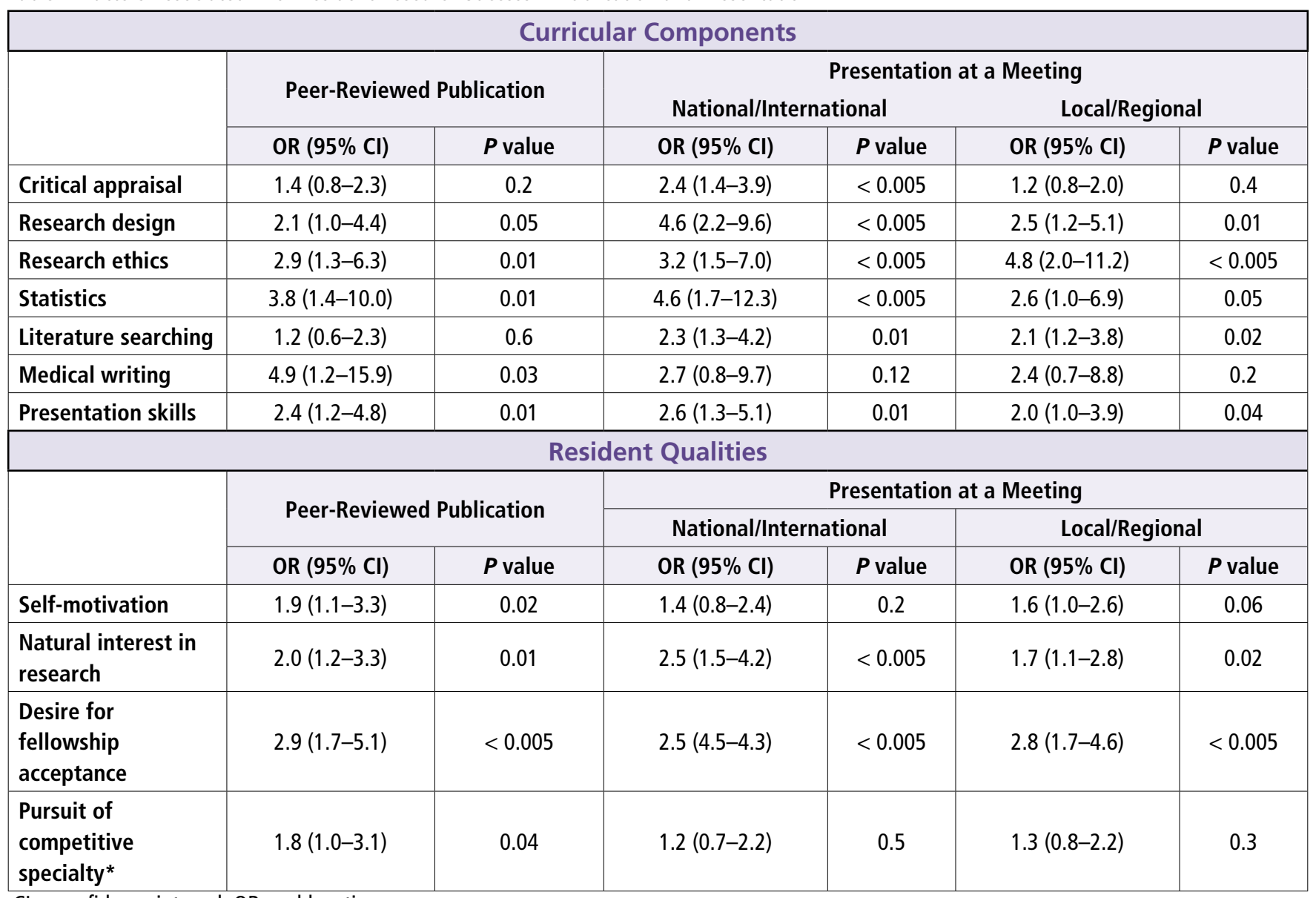

$\mathrm{Cl}=$ confidence interval; $\mathrm{OR}=$ odds ratio

${ }^{*}$ Cardiology, gastroenterology, critical care fellowships constituted competitive specialties. 


\section{Discussion}

Lack of resident and faculty time were the most significant barriers for resident research success in Canadian IM programs, while a research curriculum was identified to be a critical enabler. Thorough teaching of statistics and medical writing were most strongly associated with residents' success in achieving a publication, which is arguably the most meaningful measure of research success. Other program-related factors, including the size of the program and presence of a mandatory research project, were not significant. Self-motivation and natural interest among residents was beneficial.

Levine et al. surveyed American university and non-university IM program directors to determine how the Accreditation Council for Graduate Medical Education (ACGME) requirements for scholarly activity are fulfilled and to identify barriers to resident research. ${ }^{3}$ This is the first comparable Canadian study that defines scholar activity among IM programs and barriers to resident research, but also identifies factors that are predictive of resident research success.

The results of this study indicate that a bigger program does not equate to a better program when it comes to resident research success. Furthermore, mandating a resident research project does not impact the success of trainees; in other words, quantity doesn't mean quality. Residents who are self-motivated and naturally interested in research are likely to complete a project and publish/present their results, regardless of program requirements. The only program-related factor associated with residents' success in publication is the presence of a formal mechanism to link residents with suitable research mentors.

Residents' natural interest in research and drive to be accepted into a fellowship program are associated with their success in presenting and publishing their research projects. Although a natural interest in research cannot be contrived, selecting a project of genuine interest to the resident may be of benefit. A topic that is relevant to a resident's desired specialty should be considered, given that motivation for acceptance into a fellowship program was associated with research success.

Although it may be intuitive, this is the first study to our knowledge proving that research curricula enhance resident research success. Given that only $40 \%$ of surveyed programs have a formal scholar curriculum and $20 \%$ or fewer programs report thorough instruction on most relevant topics, this study heralds the need for a formal and enhanced scholar curricula across Canadian IM programs.

The major methodological limitation in our project is the incomplete response rate in the group of survey responders. Because a database for resident research does not exist, response bias by program directors needs to be considered.

\section{Conclusions}

This is the first study to comprehensively document research output and program requirements for scholar activity in Canadian IM programs. Based on our findings, we recommend that IM programs include a scholar curriculum with instruction on medical writing and statistics, and establish a mechanism for linking residents with suitable research mentors. Given a significant degree of variability among programs, the possibility of setting minimum requirement for scholar activity to ensure consistency in residency training across Canada should be considered.

\section{Acknowledgment}

This study did not receive funding. The authors report no conflict of interest.

Prior presentations: The final results of this study were presented at the International Conference on Residency Education on September 27, 2013.

Conflict of interest: None declared.

\section{References}

1. The CanMEDS Framework. Royal College of Physicians and Surgeons of Canada; 2013. Available: http://www.royalcollege.ca/portal/page/portal/rc/ canmeds/framework. Accessed Dec 7, 2013.

2. Schafer AI. The vanishing physician-scientist? Transl Res 2010;155:1-2.

3. Levine RB, Hebert RS, Wright SM. Resident research and scholarly activity in internal medicine residency training programs. J Gen Intern Med 2005;20:155-9.

4. Alguire PC, Anderson WA, RR Albrecht, et al. Resident research in internal medicine training programs. Ann Intern Med 1996;124:321-2.

5. DeHaven MJ, Wilson GR, O'Connor-Kettlestrings P. Creating a research culture: what we can learn from residencies that are successful in research. Fam Med 1998;30:501-7.

6. Levitt MA, Terregino CA, Lopez LB, et al. Factors affecting research directors' and residents' research experience and productivity in emergency medicine training programs. Acad Emerg Med 1999;4:356-9.

7. Rivera JA, Levine RB, Wright SM. Completing a scholarly project during residency training: perspectives of residents who have been successful. J Gen Intern Med 2005;20:366-9. 